\title{
Non-invasive diagnosis of arterial patency after thrombolytic treatment and its relation to prognosis
}

R M Norris, H D White, D B Cross, K S Woo, J M Elliott, Diana Twigden, Barbara Williams, R N Johnson study, 30 day mortality was $2 \cdot 1 \%$ in the 191 patients with three hour creatine kinase $>20 \%$ of peak and $8 \cdot 7 \%$ in the 127 patients with three hour creatine kinase $<20 \%$ of peak $(\mathrm{p}<0.01)$. Angiocardiography in three week survivors of anterior infarction $(n=95)$ showed better left ventricular function when three hour creatine kinase was $\geqslant 20 \%$ than when it was $<20 \%$ of peak (mean (SEM) end systolic volume 71 (5) $v 96$ (9) $\mathrm{ml}$, p $<0.02$; ejection fraction $56 \%(2 \%) v 51 \%$ (2\%), NS).

Conclusion-Non-invasive determination of early patency of the infarct related artery by the normalised rate of rise of creatine kinase activity at three hours seems to be reliable, and may be prognostically important and of value for use in clinical trials.

(Br Heart $\mathcal{F} 1993 ; 69: 485-491)$

Patients-Patients studied were in the following groups: (a) Sixty patients took part in a validation study with angiographic determination of patency of the infarct related coronary artery at $2.6(0 \cdot 3)$ hours (mean (SD)) after starting streptokinase. (b) A further 258 patients did not have early arteriography, but data were added to those from the 60 validation patients to find the relation between enzymatically determined early patency of the infarct related artery and 30 day mortality. (c) A further subset of 232 patients with first infarctions (including patients from groups (a) and (b) had angiocardiography at three weeks after infarction, and data were used to investigate the relation between early patency of the infarct related artery and left ventricular function.

Main outcome measures-Normalised rate of rise of creatine kinase activity at three hours after starting streptokinase in relation to angiographic patency of the infarct related coronary artery at 2.5 hours; 30 day cardiac mortality; and left ventricular function at three weeks in survivors of first infarction.

Results-In the validation study, a rise in three hour creatine kinase activity of $>20 \%$ of peak occurred in 34/37 patients with initially patent infarct related coronary arteries (sensitivity $92 \%$ ), and a rise to $<20 \%$ of peak occurred in $21 / 23$ patients with initially occluded arteries (specificity 91\%). In the prognostic
Successful thrombolytic treatment for acute myocardial infarction depends on recanalisation of occluded coronary arteries, and the standard technique for diagnosis of reperfusion has been coronary arteriography. ${ }^{12}$ Arteriography however, is invasive, expensive, and measures arterial patency at only one time. A simple reliable method for non-invasive diagnosis, if it could be shown to be prognostically meaningful, would be valuable for large scale use in therapeutic trials.

In our study we compared serial measurements of creatine kinase activity with arteriographic assessment of patency of the infarct related artery in 60 patients, paying particular attention to timing for our assessment of patency. We chose 2.5 hours rather than the more conventional 90 minutes after the start of streptokinase infusion for coronary arteriography (because of the known slower action of streptokinase than tissue plasminogen activator (alteplase) $)^{3-5}$ ) and we selected three hours after thrombolytic treatment for measurement of enzyme activity (because of an expected time lag between recanalisation and enzyme washout). A concomitant study to assess the effect of intracoronary alteplase for patients in whom intravenous streptokinase had failed to restore arterial patency ${ }^{6}$ also allowed us to assess the rate of rise of creatine kinase activity in relation to a known time of reperfusion.

We also investigated the relation between enzymically determined patency of the infarct 
related artery, 30 day mortality, and left ventricular functional impairment in a larger group of 318 patients.

\section{Patients and methods}

The study was divided into two parts that ran concurrently, a validation study and a prognostic study. Criteria for enrollment included age $<76$ years, typical chest pain starting within the previous six (mean 3.0, range $0.5-6$ ) hours, and ST segment elevation in at least two leads of the electrocardiogram of $\geqslant 2 \mathrm{~mm}$ in $\mathrm{V} 1-\mathrm{V} 3$ or $\geqslant 1 \mathrm{~mm}$ in V4-6, I, AVL, II, III, and AVF. All patients received $1.5 \times 10^{6}$ units streptokinase infused over 30-60 minutes. At the time of starting thrombolytic treatment and at $1,2,3,4,8,12,16$ 20 and 24 hours later, blood $(5 \mathrm{ml})$ was taken from an intravenous line for analysis of total creatine kinase activity by the Rosalki method. ${ }^{7}$ Intramuscular injections were avoided to prevent release of creatine kinase from skeletal muscle.

\section{VALIDATION STUDY}

Sixty patients up to 75 years of age ( 46 men, 14 women; mean age 59 , range $40-74$ years) were included in this part of the study. For comparison of the rate of release of creatine kinase with arterial patency, arteriography and left ventriculography were carried out by the Judkins technique as near as possible to 2.5 hours after starting streptokinase. Patients gave informed consent and the protocol was approved by the Green Lane Hospital ethics committee. The presumed infarct related artery was imaged first and then the other artery, and both arteries were viewed in multiple projections. After contrast injections some occluded infarct related arteries opened. In 22 patients in whom the artery was still totally or partially occluded, and as a separate study, ${ }^{\circ} 50 \mathrm{mg}$ alteplase (Actilyse, Boehringer Ingelheim) was infused directly into the infarct related artery over 10-15 minutes and the artery was imaged again immediately and after 30 minutes. At the end of the procedure a sheath was left in the femoral artery for 24 hours and heparin (1000 U/hour) was given. Patency of the infarct related artery was assessed with the thrombolysis in myocardial infarction (TIMI) criteria. ${ }^{1}$ Patency was considered as slow or rapid anterograde flow into the whole arterial supply territory (TIMI 2 or 3 ).

Patients were divided into three groups with patency of the infarct related artery at the first injection of contrast (group 1), initial occlusion but subsequent patency after further contrast injections or infusion of alteplase (group 2), and sustained occlusion with patency not seen at any time (group 3). Values for total creatine kinase activity were normalised by expressing the rise from baseline activity at each time period as a proportion of the peak rise in activity for that patient. Differences between enzyme activities and proportions in patients with open and closed coronary arteries were assessed by two sample $t$ tests.

\section{PROGNOSTIC STUDY}

Most of the 258 patients in this arm of the study were admitted concurrently with the validation patients to the coronary care units at Middlemore and North Shore Hospital where facilities for cardiac catheterisation are not available. Criteria for admission and for taking blood for enzyme measurements were $I$ identical with those for the validation patients.

Patients with first infarctions (including $\ddot{\vec{\nexists}}$ those from the validation arm) who had not been taking angiotensin converting enzyme inhibitors and who gave separately obtained informed consent were enrolled in a postinfarction trial of oral captopril $v$ placebo. This trial, which is still in progress, has the princi- कै pal end point of left ventricular volumes and $\overrightarrow{0}$ ejection fraction measured by angiocardiography at three weeks. ${ }^{8}$ Patients are discharged after about five to eight days in hospital and are readmitted as day patients for the angiocardiogram.

\section{Results}

VALIDATION STUDY

Arteriographic and clinical findings

Because of other demands on the catheterisation laboratory, it was not always possible to image the infarct related artery precisely at 2.5 hours after starting thrombolytic treatment; in the event the artery was imaged at (mean (SD)) $2.6(0.3)$ hours after starting treatment.

The infarct related artery was the left anterior descending in 31 patients, the right coronary in 26, and the left circumflex in three. It was patent (TIMI 3, 35; TIMI 2, two) in 37 $(62 \%)$ of the 60 patients at the first injection of contrast (group 1), and in a further 14 (23\%) either at a subsequent injection or after infusion of alteplase at five to 60 (mean 25) minutes after the first series of injections (group 2). The artery was not patent at any time in nine (15\%) of the patients (group 3). No serious bleeding or other untoward event occurred as a result of arteriography.

The group 1 patients with early arterial patency included six patients (group 1a) in 0 whom creatine kinase activity did not rise $N$ above $600 \mathrm{IU} / \mathrm{l}$, twice the upper normal value N for our laboratory. These patients all had $\sigma$ severe prolonged chest pain and ST segment elevation, and were indistinguishable clinically at the time of admission from patients in whom enzyme activity rose to conventionally diagnostic values. Five of the six patients had stenoses of the infarct related coronary artery (with subtotal occlusion and TIMI 2 flow in $\Omega$ one), and one had angiographically normal coronary arteries. Five of the six had normal 8 left ventricular function at ventriculography whereas the sixth patient had segmental hypokinesis. Changes in the $T$ wave without pathological $Q$ waves evolved in five patients and in one patient the electrocardiogram reverted to normal after thrombolytic treatment. 
Table 1 Total creatine kinase activity (SD) and coronary artery patency assessed by arteriography

\begin{tabular}{|c|c|c|c|c|}
\hline \multirow[b]{2}{*}{$\begin{array}{l}\text { Time after } \\
\text { thrombolytic } \\
\text { treatment (h) }\end{array}$} & \multicolumn{4}{|c|}{ Creatine kinase activity (IUII) } \\
\hline & $\begin{array}{l}\text { Group } 1 \\
\text { (patent: } n=37)\end{array}$ & $\begin{array}{l}\text { Groups } 2 \text { and } 3 \\
\text { (occluded: } n=23 \text { ) }\end{array}$ & $\begin{array}{l}\text { Group 2 } \\
\text { (patent after } \\
3 \mathrm{~h} ; n=14 \text { ) }\end{array}$ & $\begin{array}{l}\text { Group } 3 \\
\text { (persistent } \\
\text { occlusion; } n=9 \text { ) }\end{array}$ \\
\hline 0 & $177(272)$ & $156(78)$ & - & - \\
\hline 1 & $453(724)$ & 197 (124) & - & - \\
\hline 2 & $1009(1329)$ & $281(219)^{\star}$ & - & - \\
\hline 3 & $1377(1551)$ & $404(348)^{\star \star}$ & - & - \\
\hline 4 & $1826(1876)$ & - & $1034(964)$ & $686(531)$ \\
\hline 8 & 2407 (1967) & - & $3195(2716)$ & $2066(1969)$ \\
\hline 12 & $2112(1684)$ & - & $2841(1846)$ & 2831 (1609) \\
\hline 16 & $1927(1507)$ & - & 2419 (1544) & 3018 (1589) \\
\hline 20 & $1533(1113)$ & - & $2521(1911)$ & 2309 (697) \\
\hline 24 & $1261(916)$ & - & $1880(1002)$ & $2898(2352)$ \\
\hline Peak value & 2547 (2058) & - & 3609 (2626) & $3917(2242)$ \\
\hline Time to peak (h) & $8.6(4.3)^{\star}$ & - & $11.9(5.4)^{\star}$ & $17 \cdot 8(6 \cdot 4)$ \\
\hline
\end{tabular}

${ }^{\star} \mathrm{p}<0.05 ;{ }^{\star \star} \mathrm{p}<0.01$ compared with adjoining group.

Relation of creatine kinase activities to arterial patency

Table 1 shows the mean (SD) for total creatine kinase activity at each time for each of the three groups of patients. As expected, there was an enormous variation indicated by the high SDs that in some cases exceeded the mean values. Individual patients showed a 40-fold variation from the lowest to the highest peak values. Activities in all but two patients showed a consistent pattern, each consecutive specimen being a higher level than the preceding specimen up to a peak, followed by a steady fall for patients in whom activity peaked before 24 hours. Despite the wide range of values shown in table 1 there were significant differences between enzyme activities in patients with patent arteries and those with occluded arteries at two and three hours after thrombolytic treatment, and in the times to peak activity between the three groups of patients.

Four of the six group 1a patients in whom enzyme activity did not rise above twice the upper limit of normal also showed a rise that occurred through the normal range to a peak within eight hours of thrombolysis, followed by a fall to resting values of $100-250 \mathrm{IU} / 1$ by 24 hours. The peak activity exceeded twice the baseline in three of these four patients and was slightly less than twice the baseline in the fourth. The remaining two patients showed a peak in the baseline specimen that fell gradually over 12-24 hours to resting values of less than half the baseline.

Figure 1 Rise in creatine kinase (CK) activity from baseline expressed as a proportion of peak rise for the three groups of patients who had early arterial patency (group 1), restored patency (group 2), or sustained occlusion (group 3). Groups 2 and 3 are not separated until after three hours. Bars indicate SEM. ${ }_{*}<0.05 ;{ }^{\star *} p<0.01$; $x_{* * * p}<0.001$.
Figure 1 shows normalised values for the three groups of patients from one to 12 hours after thrombolytic treatment. Significant differences in proportions of the enzyme occurred between group 1 and 2 patients at one, two, and three hours after treatment and between group 2 and 3 patients at four, eight, and 12 hours after treatment.

Figure 2 shows the proportion of peak creatine kinase activity in the three hour specimen from patients in groups 1,2 , and 3. Good discrimination is shown, $34(92 \%)$ of the 37 group 1 patients, including all six group 1a patients with a non-diagnostic enzyme rise, showed a three hour creatine kinase of $>20 \%$ of peak. Three hour creatine kinase was $<20 \%$ in $21(91 \%)$ of the 23 patients in groups 2 and 3 who had coronary occlusion at first imaging by coronary arteriography.

Relation between time of restoration of arterial patency and enzyme washout

Of the 14 group 2 patients who had restoration of patency of the infarct released artery either by contrast or by intracoronary infusion of alteplase, patency occurred before taking the four hour blood specimen in 11. To examine the rate of enzyme release and the lag phase with restoration of patency, we plotted the three and four hour values for creatine kinase activity as a percentage of the peak for these 11 patients (fig 3), comparing them with nine patients seven group 3 , two group 2) in whom four hour enzyme activities were available and the artery was known to have remained occluded at that time. Also, fig 3 shows the three and four hour values for the three patients with early patency who had a three-hour washout of $<20 \%$ (shown in fig 2).

There was a much more rapid rise in activity as a percentage of the peak in patients with restored patency over this one hour period (mean $20 \%$ rise, range $7 \%-36 \%$ ) than in patients with sustained occlusion (mean $4 \%$ rise, range $0 \%-8 \%$ ). The three patients who had early patency but a low three-hour enzyme washout also showed a rapid washout between three and four hours (mean $29 \%$, range $25 \%-33 \%$ ) similar to that shown by patients with restored patency. Thus in these patients the four-hour rather than the threehour sample indicated patency. Review of the records showed that the arteriogram had been somewhat delayed in these patients so that in two patients the three-hour blood had been taken five minutes before imaging of the artery (instead of 30 minutes after imaging as intended) whereas in the third patient the blood had been taken only 12 minutes after imaging. If in these patients the vessel had opened only shortly before the artery was imaged, such delay might have allowed insufficient time for enzyme activity to rise in the systemic circulation.

Defibrillation and total creatine kinase activities Because cardiopulmonary resuscitation from ventricular fibrillation can cause an increase 


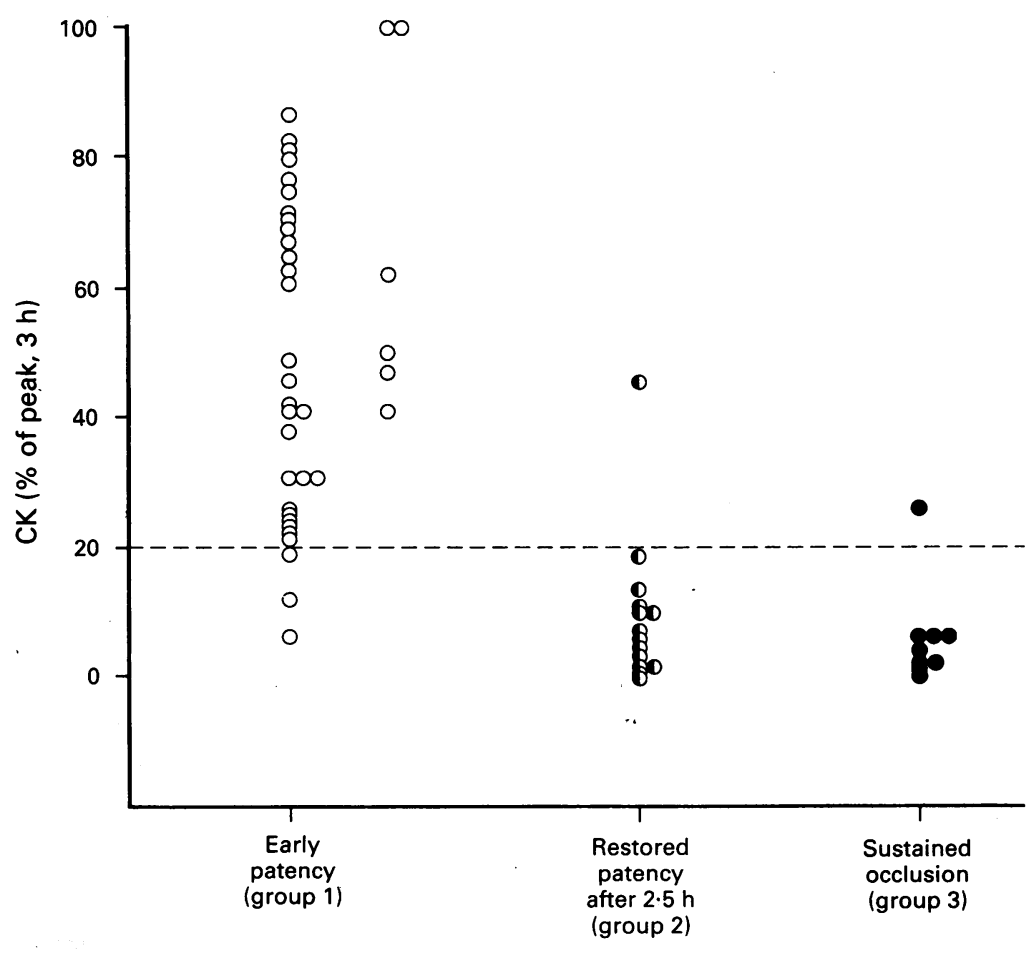

Figure 2 Rise in three hour creatine (CK) activity from baseline expressed as proportion of peak rise according to whether the infarct related artery was patent (group 1) or occluded (groups 2 and 3) at first arteriographic imaging. Patients with patent arteries and a non-diagnostic enzyme rise (group 1 a) are shown to the right of group 1.

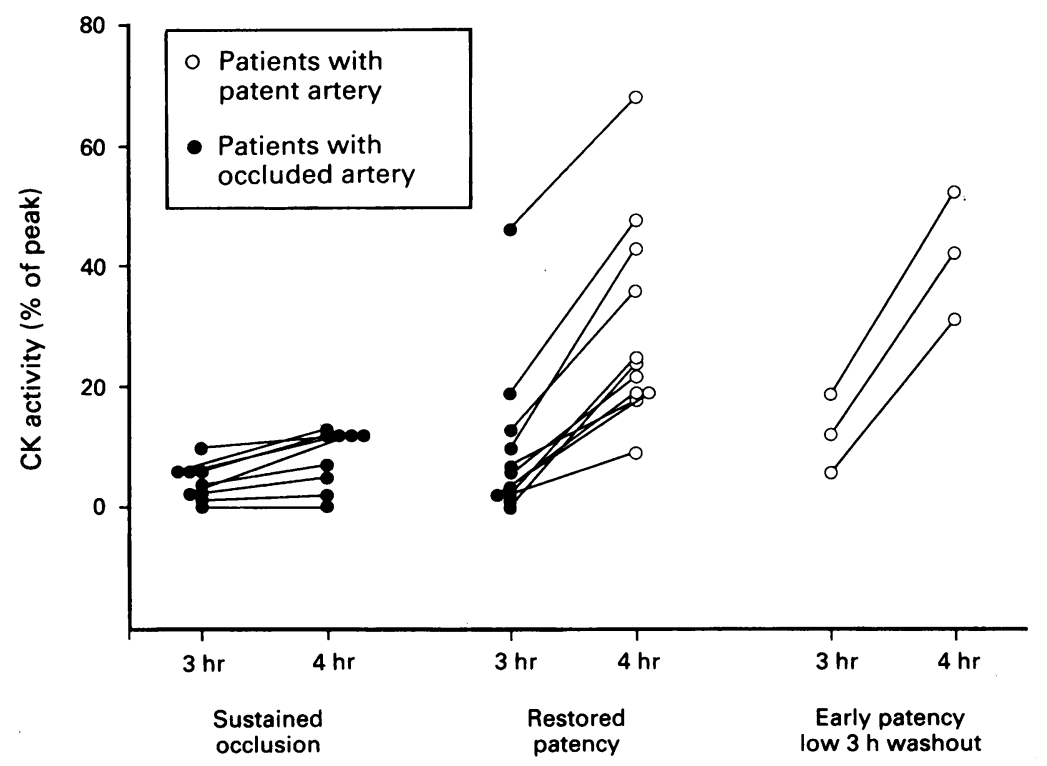

Figure 3 Increase in creatine kinase (CK) activity as \% of peak in patients with sustained arterial occlusion at four hours, in those with restored arterial patency between three and four hours, and in the three patients with patency at three hours whose rise in enzyme activity at three hours was $<20 \%$ of peak.

Table 2 Clinical characteristics (mean (SD)) of patients with and without early patency of infarct related artery after streptokinase ( $3 \mathrm{~h}$ creatine kinase (CK) activity $>20 \%$ or $<20 \%$ of peak)

\begin{tabular}{lccc}
\hline & $\begin{array}{c}\text { Early arterial } \\
\text { patency }(n=191)\end{array}$ & $\begin{array}{c}\text { Early arterial } \\
\text { occlusion }(n=127)\end{array}$ & $p$ Value \\
\hline Age (yr; mean (SD)) & $58(10)$ & $60(9)$ & $0 \cdot 01$ \\
Male Sex (\%) & 79 & 71 & $0 \cdot 1$ \\
Anterior infarction (\%) & 47 & 41 & NS \\
Previous infarction (\%) & 8 & 6 & NS \\
Current smoker (\%) & 40 & 39 & NS \\
Diabetic (\%) & 10 & $3 \cdot 1(1 \cdot 2)$ & NS \\
Time to streptokinase (h; mean (SD)) & $3 \cdot 0(1 \cdot 4)$ & $2732(1825)$ & $<0 \cdot 05$ \\
Peak CK (IU/1; mean (SD)) & $2750(2103)$ & 5 & NS \\
Peak CK <600 U/1 (\%) & 12 & 7 & $0 \cdot 1$ \\
Ventricular fibrillation & 5 & 2 & \\
during sampling period (\%) & 6 & & \\
Reinfarction in hospital (\%) & & & \\
\hline
\end{tabular}

in creatine kinase activity as a result of release from chest wall muscle we examined enzyme activities in relation to defibrillation. Ventricular fibrillation occurred in 10 patients; before entry to the study in one and within four hours of entry in the other nine. Defibrillation without prolonged cardiopulmonary resuscitation was successful in all patients.

Five patients developed ventricular fibrillation in the catheterisation laboratory, in four patients (group 2) at the time that a blocked coronary artery was seen to reopen and in one patient (group 1) shortly before an open infarct related artery was imaged. In all five cases, ventricular fibrillation preceded a rapid rise in enzyme activity, and the arrhythmia was apparently associated with reperfusion. In the other five patients who had occluded arteries at arteriography, no rise in enzymes occurred within two hours of defibrillation, so that the arrhythmia appeared to be associated with persisting coronary occlusion. In no case did it seem that there had been a rise in creatine kinase activity due to release of enzyme from the heart or skeletal muscle as a result of defibrillation.

\section{PROGNOSTIC STUDY}

Of the total group of 318 patients, 241 were men and 77 were women. The mean age was 59 (range 27-75 years) and time from the start of chest pain was 3.0 (range $0.5-6$ ) hours. There were no significant differences in clinical characteristics at entry between the 258 patients who did not have angiography and the 60 patients who did (data not shown).

One hundred and ninety one $(60 \%)$ of the 318 patients had early arterial patency indicated by three hour creatine kinase $\geqslant 20 \%$ of

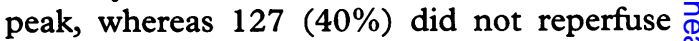
early as judged by three hour creatine kinase $\stackrel{\varrho}{\beth}$ $<20 \%$ of peak. Table 2 shows the clinical $\frac{5}{5}$ characteristics of the two groups of patients. Patients who did not reperfuse early were $\delta$ older (60 (9) $v 58(10)$ years; $\mathrm{p}=0.01)$ and were less likely to be regarded as not develop- $\frac{\rho}{5}$ ing infarction on the grounds that peak activi- $\rightarrow$ ty was less than twice the upper limit of normal ( $5 \% v 12 \%$; $<<0.05)$.

Figures 4 and 5 shows the important end $N$ points of mortality and left ventricular func- N tional impairment for patients who did or did not have early patency of the infarct related artery. Thirty day mortality was $2 \cdot 1 \%$ for patients with early arterial patency and $8.7 \% \stackrel{\text { ? }}{\rightarrow}$ for patients without reperfusion $(p<0.01 ; 0$ fig 4$)$. The $95 \%$ confidence interval $(95 \% \mathrm{CI}) \stackrel{\mathrm{O}}{\circ}$ for the mortality difference $6.6 \%$ was $\stackrel{\odot}{\square}$ $1 \cdot 3 \%-11 \cdot 9 \%$. Figure 5 shows the left ventric- $\stackrel{\mathbb{Q}}{\mathscr{Q}}$ ular function in surviving patients with anterior and inferior infarction. Patients with an 8 anterior infarction that did not reperfuse early응 had more dilated ventricles than those with early arterial patency (end systolic volume $96 \stackrel{0}{5}$ (9) $v 71$ (5) $\mathrm{ml}, \mathrm{p}<0.02$; end diastolic volume $193(14) v 153(7) \mathrm{ml}, \mathrm{p}<0.01$; ejection fraction $51 \%(2 \%) v 56 \%(2 \%) \mathrm{NS})$. Patients with inferior infarction did not, how- 
Figure 430 day mortality of patients with and without early patency of the infarct related artery as judged by the three hour creatine kinase (CK) washout.

Figure 5 Left ventricular volumes and ejection fractions of 95 patients with anterior infarction $(A)$ and of 131 patients with inferior infarction $(B)$ who did or did not have early patency of the infarct related artery as judged by the three hour creatine kinase washout. Bars indicate SEM. Numbers within the histograms indicate the number of patients in each group.

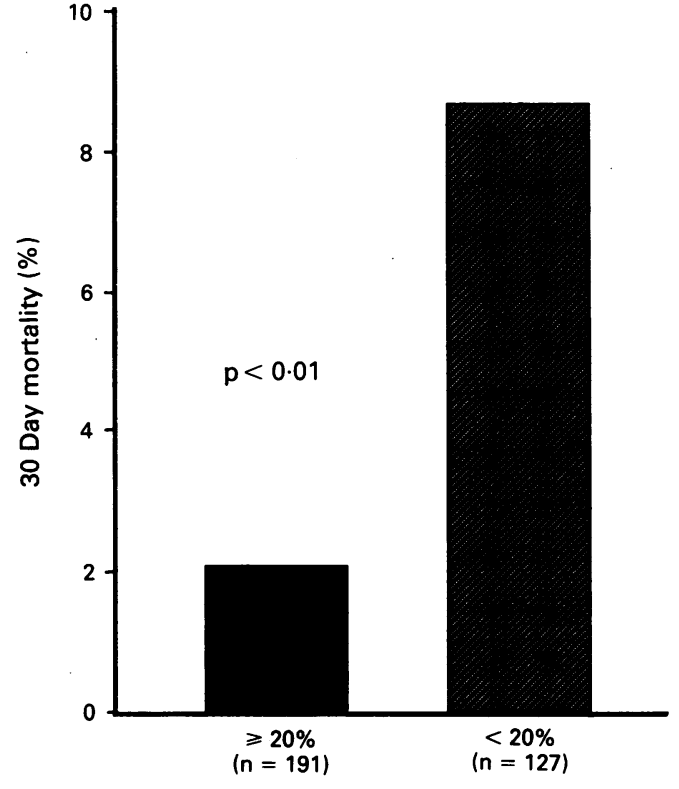

CK washout $(3 \mathrm{~h})$
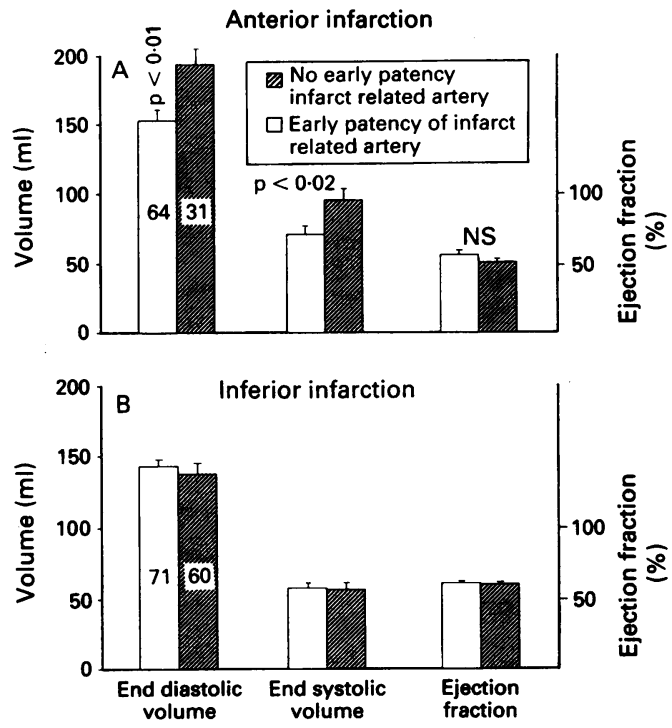

ever, show greater impairment of left ventricular function with failed reperfusion (end systolic volume 58 (3) $v 57$ (4) $\mathrm{ml}$; end diastolic volume $143(5) v 138(7) \mathrm{ml}$; ejection fraction $61 \%(1 \%) v 60 \%(1 \%)$.

\section{Discussion}

Current regimens for giving streptokinase result in an increase in rates of arterial patency from about $20 \%$ to $80 \%$ during the first 24 hours after infusion. ${ }^{3-5}$ To assess new adjunctive treatments or to compare different thrombolytic agents it is essential to develop non-invasive tests that give reliable information about reperfusion at a definite time. Comparisons of the mean time to peak enzyme release in groups may indicate differ- ences between eventual patency rates,' but the time to peak enzyme release is not a reliable indicator of the timing of reperfusion in individual patients.

Use of the rise in total creatine kinase activity at three hours from the start of treatment with streptokinase expressed as a proportion of the peak rise emerges from this study as a simple and reliable marker of patency of the infarct related coronary artery at about 2.5 hours after starting treatment. The three hour normalised value was $\geqslant 20 \%$ of peak in 34/37 patients in whom the infarct related artery was patent (sensitivity 92\%) and it was $<20 \%$ in $21 / 23$ in whom the artery was occluded (specificity $91 \%$ ). Patients with the clinical syndrome of acute myocardial infarction but a non-diagnostic enzyme rise were correctly identified as having patent infarct related arteries. Moreover, the test remained reliable for patients who had defibrillation without prolonged cardiac resuscitation.

Enzyme activities rise rapidly after reperfusion occurs (fig 3), so that blood specimens must be taken at strictly defined times (within limits of perhaps 10-15 minutes) to define these changes. The three apparently false negative results in patients with patent arteries (fig 2) in our study were likely because of an unduly short period between attainment of patency and collection of the three-hour blood specimen (the four hour specimens indicating patency). If this is so, the sensitivity of our method could be even higher than $92 \%$.

The clinical relevance of the enzymatic method is supported by results of the prognostic study. The higher hospital mortality for patients with delayed enzyme rise is not explicable by differences in entry characteristics. The sample of patients who underwent three-week angiocardiography was biased against inclusion of patients without early reperfusion because their early mortality was higher. Despite this, patients without reperfusion and anterior infarction showed greater ventricular dilatation than patients with anterior infarction and early patency. Patients with inferior infarction did not show greater impairment of function without reperfusion, presumably because the volume of myocardium at risk is usually less with inferior than with anterior infarction. ${ }^{10}$

Despite convincing earlier findings of a rapid rise in enzyme activity at the time of reperfusion both in experimental infarcts ${ }^{11}$ and in patients with infarction, ${ }^{1213}$ some recent studies have concluded that simple enzymatic tests show a predictive accuracy that is insufficient to justify their routine clinical use, ${ }^{14}$ or is inferior to that which can be obtained from the more laborious measurement of creatine kinase isoforms. ${ }^{15}$ In two of the earlier studies performance of coronary angiography before giving thrombolytic treatment enabled the rise in enzyme activity to be calculated from a known time of reperfusion, and showed clear differentiation between patients who reperfused and those who did 
not. ${ }^{12}$ Because it is no longer justifiable to perform angiography before thrombolysis, this type of study can no longer be performed routinely. Giving of rescue thrombolysis by the intracoronary route in our study (fig 3) did, however, allow us to confirm these earlier results in 20 patients. In our opinion, the failure of the two recent studies to show an acceptable predictive accuracy for cutoff points of enzyme washout could be because the rates of rise were not normalised to the wide range of peak activities found..$^{14} 15$ For instance a rise in activity of $200 \mathrm{IU} / 1$ over three hours when the peak was $600 \mathrm{IU} / 1$ would indicate reperfusion according to our calculations, whereas a rise in $200 \mathrm{IU} / 1$ when the peak was $6000 \mathrm{IU} / 1$ would not.

An alternative to the simple normalisation of values that we propose would be use of a model in which the fractional appearance rates $(\mathrm{Ka})$ and disappearance rates $(\mathrm{Kd})$ of enzyme activity are calculated. ${ }^{16}$ To find the $\mathrm{Kd}$ necessitates blood sampling over $\mathbf{4 8}$ hours or more, which is irksome and inconvenient for patients and nurses. In our experience, variation in $\mathrm{Kd}$ among individual patients would be unlikely to influence the much greater differences in $\mathrm{Ka}$ between infarcts that reperfuse and those that do not. ${ }^{17}$

The most important disadvantage both of our method and of the appearance/disappearance model is that the diagnosis of arterial patency in individual patients is necessarily retrospective because the proportion of enzyme release cannot be calculated until the peak value is known. Thus these methods are not applicable for the rapid diagnosis of success or failure of thrombolytic treatment in individual patients. Possible discrepancies between non-invasively diagnosed reperfusion and angiographically defined patency include failure of tissue reperfusion despite restoration of patency of the infarct related artery, reperfusion by collaterals despite persistent occlusion, and uncertainty about angiographic grading of patency, particularly for TIMI 3 $v$ TIMI 2 lesions. ${ }^{18}$ Clearly we have insufficient cases in our study to say whether or not such events occur in practice. If they did occur, however, it could be argued that reperfusion diagnosed by the enzymatic method is of greater clinical relevance than recanalisation diagnosed by angiography.

Total creatine kinase is easily measurable, does not deteriorate rapidly with storage at room temperature or from contact with red cells, shows a consistent and accurately quantifiable rise and fall after myocardial infarction, ${ }^{17}$ and is sensitive to the effects of therapeutic agents. ${ }^{19}$ The method we now describe required 10 blood specimens that were taken without discomfort to the patients from the intravenous line. It would be possible to reduce this number to seven by taking blood at baseline, at three hours and then every four hours from eight to 24 hours for detection of the peak value. At a cost of about $20 \mathrm{p}$ a test for reagents this is a fully automated and cost effective investigation that can be performed in most hospital laboratories.
Although measurement of the cardiac selective creatine kinase $\mathrm{MB}$ is favoured by other workers, ${ }^{1213}$ we think that separation of the $10 \%$ or so of cardiac selective activity for assessment of arterial patency in patients with known infarction in whom intramuscular injections are avoided is unnecessary and $\underline{\underline{m}}$ could in fact diminish sensitivity because of $I$ the lower activities that can be measured.

Reduction of cardiac mortality and preser- $\frac{\vec{c}}{c}$ vation of left ventricular function for survivors of infarction remain the important $\stackrel{\vec{S}}{\rightarrow}$ goals of thrombolytic treatment. The method $\bar{c}$ we now describe for non-invasive diagnosis of $\overline{\bar{\sigma}}$ early patency of the infarct related artery cor- $\frac{\omega}{\partial}$ relates both with 30 day mortality and with $\mathscr{\Phi}$ impairment of left ventricular function, at $\aleph^{2}$ least for patients with anterior infarction. $\vec{\circ}$ Early patency of the infarct released artery is clearly an important end point for assessment $\vec{\omega}$ of thrombolytic efficacy. Randomised clinical $\frac{\rho}{\partial}$ trials for testing an increasing number of thrombolytic and adjuvant agents continue to 6 be necessary, but current trials with cardiac mortality as an end point require enrolment of of more than 40000 patients. ${ }^{20}$ Total creatine $ᄋ$ kinase activity can be measured easily in any general hospital laboratory, and use of early $\bar{c}$ arterial patency determined by this method $\frac{\bar{\sigma}}{\sigma}$ could provide meaningful comparisons of dif- $\vec{\theta}$ ferent regimens by study of hundreds rather $\Theta$ than tens of thousands of patients.

We are indebted to Drs $T$ M Agnew, $H$ A Coverdale, W $M$ Jaffe, A H G Roche, and W M Smith for performing some of the coronary arteriograms and to Mrs Carol Caunter for typ- O ing the manuscript. We are particularly grateful to the nursing ing the manuscript. We are particularly grateful to the nursing and North Shore Hospitals without whose help the study would have been impossible, and to Drs A Maslowski, M $\overrightarrow{\vec{\sigma}}$ Caruana, H H Hart, and E D Clarke who kindly allowed us to study patients under their care. The study was supported by the Medical Research Council and the National Heart Foundation of New Zealand.

1 The TIMI Study Group. The thrombolysis in myocardial infarction (TIMI) trial. Phase I findings. $N$ Eng 7 Med infarction (TIMI)

2 European Co-operative Study Group. Randomised trial of intravenous recombinant tissue-type plasminogen acti- $\delta$ vator versus intravenous streptokinase in acute myocar- $\frac{0}{3}$ dial infarction. Lancet 1985;1:842-9.

3 PRIMI Trial Study Group. Randomised double-blind trial 응 of recombinant pro-urokinase against streptokinase in acute myocardial infarction. Lancet 1989;i:863-8. 4 White HD. GISSI-2 and the heparin controversy. Lancet 을.
1990;336:297-8.

5 Sherry S, Marder VJ. Streptokinase and recombinant tis- N sue plasminogen activator (rt-PA) are equally effective in treating acute myocardial infarction. Ann Intern Med N 1991;114:417-23.

6 White HD, Cross D, Williams B, Norris R. Patency rates N after intravenous streptokinase, intravenous contrast $\sigma$ and intracoronary rt-PA [abstr.]. Aust NZ 9 Med 1991; 21:555.

7 Rosalki SB. An improved method for creatine phosphokinase determination. F Lab Clin Med 1967;69:696-705. 8 White HD, Norris RM, Brown MA, Brandt PWT, $\stackrel{\text { ? }}{?}$ Whitlock RML, Wild CJ. Left ventricular end-systolic $\square$ volume as the major determinant of survival after recov-

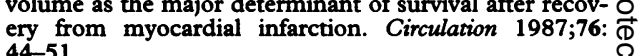

The ISAM Study Group. A prospective trial of intra- $\mathbb{D}^{+}$ venous streptokinase in acute myocardial infarction (ISAM). N Engl F Med 1986;314:1465-71.

10 Christian TF, Gibbons RJ, Gersh BJ. Effect of infarct location on myocardial salvage assessed by technetium- 8 $99 \mathrm{~m}$ isonitrile. F Am Coll Cardiol 1991;17:1303-8.

11 Vatner SF, Baig H, Manders WT, Maroko PR. Effects of coronary artery reperfusion on myocardial infarct size calculated from creatine kinase. $\mathcal{f}$ Clin Invest 1978; 61:1048-56.

12 Lewis BS, Ganz W, Laramee P, Cercek B, Hod H, Shah PK, et al. Usefulness of a rapid initial increase in plasma creatine kinase activity as a marker of reperfusion during thrombolytic therapy for acute myocardial infarction. Am $¥$ Cardiol 1988;62:20-4. 
13 Garabedian HD, Gold HK, Yasuda T, Johns JA, Finkelstein DM, Gaivin RJ, et al. Detection of coronary artery reperfusion with creatine kinase-MB determinations during thrombolytic therapy: correlation with acute angiography. 7 Am Coll Cardiol 1988;11:729-34.

14 Barker HA, van der Laarse A, Manger Cats V, Bruschke AVG. Are enzymatic tests good indicators of coronary reperfusion? Br Heart $\mathcal{f}$ 1992;67:150-4.

15 Schafer J, Ross-Grigolo G, Voigt KD, Mathey DG. Early detection of coronary artery patency after thrombolysis by determination of the MM creatine kinase isoforms in patients with acute myocardial infarckinase isoforms in patients with acute
tion. Am Heart $₹$ 1992;123:846-52

16 Ong L, Coromilas J, Zimmerman JM, Green S, Padmanabhan V, Reiser $\mathrm{P}$, et al. A physiologically based model of creatine kinase-MB release in reperfusion of acute myocardial infarction. Am f Cardiol 1989;64:11-5.

17 Norris RM, Whitlock RML, Barratt-Boyes C, Small CW.
Clinical measurement of myocardial infarct size: modification of a method for the estimation of total creatine phosphokinase release after myocardial infarction. Circulation 1975;51:614-20.

18 Karagounis L, Sorensen SG, Menlove R, Moreno F, Anderson $\pi$. Does thrombolysis in myocardial infarction (TIMI) perfusion orade 2 represent a mostly patent artery or a mostly occluded artery? $\mathfrak{f} \mathrm{Am}$ Coll Cardiol 1992;19:1-10.

19 Peter T, Norris RM, Clarke ED, Heng MK, Singh BN, Williams B, et al. Reduction of enzyme levels after acute Whams $\mathrm{B}$, et al. Reduction of enzyme levels after acute 1978;57:1091-5.

20 Topol EJ, Armstrong $P$, Van de Werf F, Kleiman N, Lee $\mathrm{K}$, Morris $\mathrm{M}$, et al. Confronting the issues of patient safety and investigator conflict of interest in an international clinical trial of myocardial infarction. $f \mathrm{Am}$ Coll Cardiol 1992;19:1123-8. 